$16^{\text {th }}$ International Conference on

AEROSPACE SCIENCES \& AVIATION TECHNOLOGY,

$\boldsymbol{A S A T}$ - 16 - May 26 - 28, 2015, E-Mail: asat@mtc.edu.eg

Military Technical College, Kobry Elkobbah, Cairo, Egypt

Tel : +(202) 24025292 - 24036138, Fax: +(202) 22621908

\title{
Power Factor Improvement Using a Three Phase Shunt Active Power Filter
}

\author{
S. Abdelrazik ${ }^{*}$, TH. Elshater ${ }^{\dagger}$ and Y. Abdalla ${ }^{\ddagger}$
}

\begin{abstract}
The increasing growth in the use of electronic equipment in recent years has resulted in a greater need to ensure that the line current harmonic content of any equipment connected to the ac mains is limited to meet regulatory standards. Shunt Active Power Filters (SAPF) are used to compensate both harmonic and reactive current component for the power supplies. It also improves the power quality and power factor on power utility. In this paper, Application of Direct Testing and Calculating Method (DTCM) in Shunt Active filters is proposed to estimate reference current signal, and apply hysteresis control to generate gate pulses. The results of simulation study of control scheme presented in this paper is found quite satisfactory for eliminate harmonics and reactive power components from utility, successful in meeting the IEEE 519 recommended harmonic standard limits.
\end{abstract}

Keywords: Shunt Active Power Filters, Harmonic currents, reference Current signal, hysteresis control.

\section{Nomenclature}

$\mathrm{K}_{\varphi} \quad$ displacement factor

$\mathrm{K}_{\mathrm{d}} \quad$ distortion factor

$\mathrm{i}_{\mathrm{p}} \quad$ active current component

$\mathrm{i}_{\mathrm{q}} \quad$ reactive current component

$\mathrm{i}_{\mathrm{h}} \quad$ harmonic load current

$\mathrm{I}_{\mathrm{F}} \quad$ reference current signal

$I_{S}^{*} \quad$ the estimated current

$\mathrm{I}_{\mathrm{L}} \quad$ load current signal

$\alpha$ phase shift angle

$H$ a signal deviation

$I_{f}^{*}$ Reference Current signal

\footnotetext{
Teaching Assistant, Faculty of Industrial Education, Helwan University, Cairo, Egypt, Mohamed_samar47@yahoo.com

${ }^{\dagger}$ Associate Professor, Faculty of Industrial Education, Helwan University, Cairo, Egypt, elshater_thanaa@yahoo.ca

Teacher, Faculty of Industrial Education, Suez University, Suez Egypt, dreng.yasser@yahoo.com
} 


\section{Introduction}

Modern electrical systems cause an increasing harmonic disturbance in the ac main currents, due to wide spread of power conversion units and power electronics equipments. These harmonic currents cause adverse effects in power systems such as overheating, perturbation of sensitive control and communication equipment, capacitor blowing, motor vibration, excessive neutral currents, resonances with the grid and low power factor [1].

The power factor values measures how much the mains efficiency is affected by both phase lag $\varphi$ and harmonic content of the input current. Its value lies in the range between 0 and 1 and it is computed as the ratio of the real power to the apparent power. Power Factor can be calculated as:

$$
P F=\frac{P}{S}=\frac{V_{r m s} \times I_{1 r m s} \times \cos \varphi_{1}}{V_{r m s} \times I_{r m s}}=\frac{I_{1 r m s}}{I_{r m s}} \times \cos \varphi_{1}=K_{d} \times K_{\varphi}
$$

Where,

$K_{\varphi}$ is the displacement factor $=\cos \varphi_{1}$

$$
, K_{d} \text { the distorition factor }=\frac{I_{1 r m s}}{I_{r m s}}
$$

Another important parameter that measure the percentage of distortion is known as the Current Total Harmonic Distortion (THD ) which is defined as follows:

$$
T H D=\frac{\sqrt{I_{2 r m s}^{2}+I_{3 r m s}^{2}+\cdots+I_{n r m s}^{2}}}{I_{1 r m s}}
$$

From equations (2), (4) we get the relationship between the THD and the $\mathrm{K}_{\mathrm{d}}$ :

$K_{d}=\frac{1}{\sqrt{1+T H D^{2}}}$

Where: $I_{r m s}=\sqrt{I_{1 r m s}^{2}+I_{2 r m s}^{2}+I_{3 r m s}^{2}+\cdots+I_{n r m s}^{2}}$

Harmonic distortion in power distribution systems can be suppressed using two approaches namely, passive and active powering. The passive filtering is the simplest conventional solution to mitigate the harmonic distortion [2,3]. Although simple, passive filters have many disadvantages, such as large size, resonance, and fixed compensation characteristics. Therefore, it does not provide a complete solution [4]. In order to solve these problems, the concept of APF was presented. Active power filters, which compensate harmonic and reactive current component for the power supplies, can improve the power qualities and improve the power factor on power utility. In recent 40 years from APF presented, the continual innovation of control strategies mainly impels the APF techniques to be developed rapidly.

In the active filter a controller determines the harmonics that are to be eliminated and generates appropriate gating signals for the inverter. Many harmonic detection techniques for active power filters have been studied. In frequency domain, Discrete Fourier Transform (DFT) and Fast Fourier Transform (FFT) have been widely used [5,6]. The main disadvantage of these techniques is the time delay associated with sampling and computation of Fourier coefficients, which makes them difficult for real-time application on dynamically varying load [7]. On the other hand, the time domain methods require less calculations and are widely 
followed for computing the reference current. The time-domain methods include, instantaneous reactive power theory p-q method [1 and 7-11], Synchronous Reference Frame (SRF) [12, 13], Direct Testing and Calculating Method (DTCM) and Notch Filtering. This paper presents modeling and simulation of a direct testing and calculating control algorithm of active power filter using MATLAB Simulink. Direct testing and calculating control algorithm offers an advantage to compensate the harmonics generated through the load application [14]. The proposed scheme provides an additional feature over compensating harmonics only by compensating both harmonics and reactive power simultaneously.

\section{SAPF Operating Principles}

Many researches have been carried out to find the best performed control strategy for the shunt APF. However, before developing the controller, the basic concept of active filter control used in the design has to be defined. Operating principle of shunt APF depends on providing reactive power and harmonic components of load current. By this way, filter and load together behaves like a resistive load and only fundamental component of load current in phase with voltage is drawn from ac mains [15]. If the load current $\left(I_{L}\right)$ is $i_{p}+i_{q}+i_{h}$ where $i_{p}$ is the fundamental active component, $i_{\mathrm{q}}$ is the reactive component and $i_{h}$ is the harmonic load current, then the SAPF should inject a negative current of amplitude $\left(i_{q}+i_{h}\right)$ to obtain the active component $i_{p}$ only, which is sinusoidal and in phase with the mains voltage. A description of the SAPF components as shown in Fig.1 is the voltage source inverter (VSI), the control unit, the modulation unit, the DC link is a capacitor $(\mathrm{C})$ as storage energy, and the inductors $\left(\mathrm{L}_{\mathrm{f}}\right)$. The control unit generates the reference currents of the shunt APF. The reference current signal $\left(\mathrm{I}_{\mathrm{F}}\right)$ and the estimated current $\left(I_{S}^{*}\right)$ are the inputs to the modulation unit to generate the gating signals for the VSI [16].

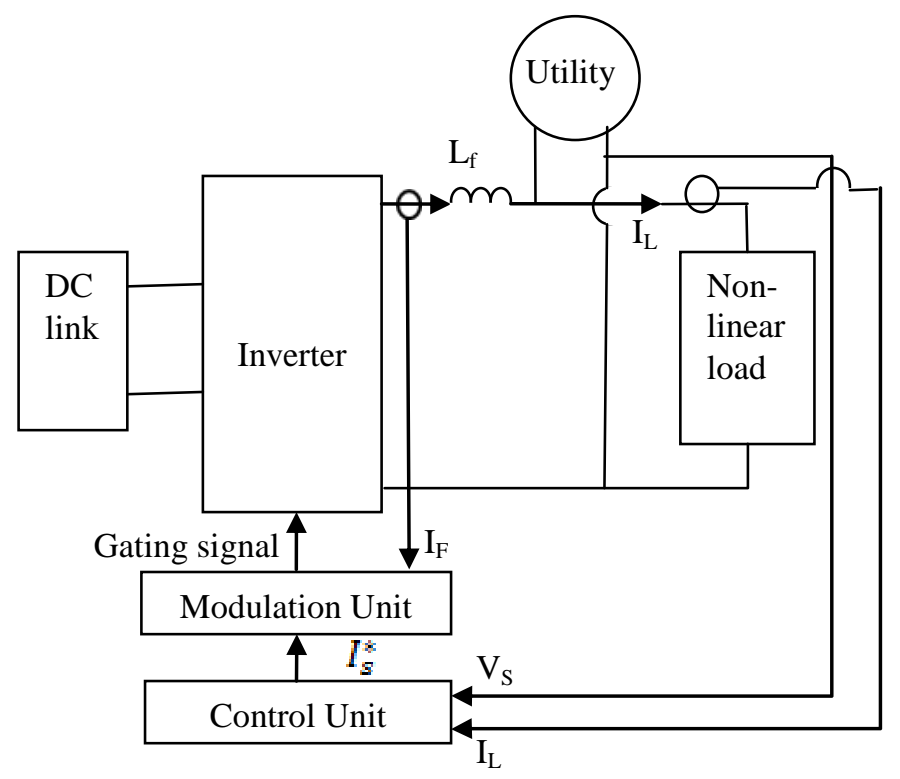

Fig. 1 Three-phase shunt APF

\section{Proposed Method}

The control strategies of the active filters are implemented mainly in three steps: Signal measuring, generating the reference signal and generation of gating signals for switching devices. The proposed method for generating the reference current signal is Direct Testing and Calculating Method (DTCM). Which is used widely in the signal processing in recent 
years. This reference current signal is fed to the hysteresis current control to have the PWM pulses. Fig. 2 Shows block diagram of the proposed system.

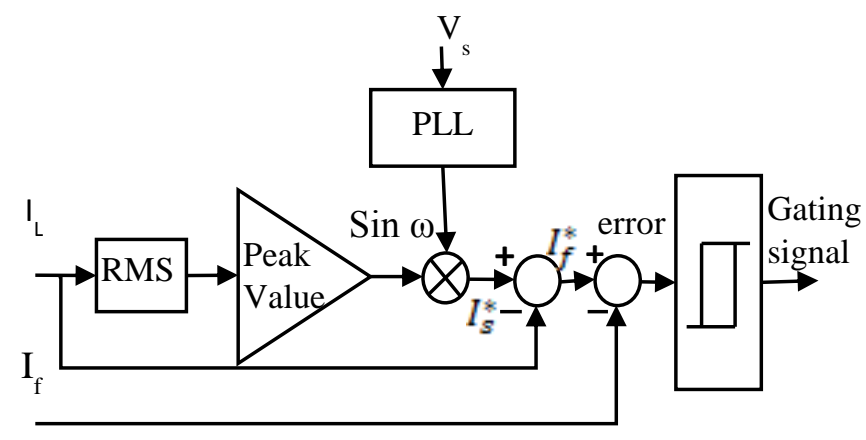

Fig. 2 Block diagram of the proposed system

The proposed scheme provides an additional feature over compensating harmonics only [14] by compensating both harmonics and reactive power simultaneously. The PLL generates a signal $(\omega)$ synchronized with the fundamental component of load current $\left(\mathrm{I}_{1 \mathrm{rms}}\right)$ [14]. The power factor (P.F) in this case is less than unity as explained in the following equations.

$P . F=\frac{I_{1 r m s}}{I_{s r m s}} * \cos \alpha$

Where $I_{s}^{*}=I_{1 r m s} \quad, \alpha=\varphi$

$P . F=\cos \varphi$

Where $\alpha$ is phase shift angle of required source current $\left(I_{S}^{*}\right)$ and in phase with load current. While in our case the power factor is equal to unity.

Where $I_{s}^{*}=I_{1 r m s} \quad, \alpha=0$

$P . F=1$

Where $\alpha$ is phase shift angle of required source current $\left(I_{S}^{*}\right)$ and in phase with source voltage.

\section{1 . Direct Testing and Calculating Method (DTCM)}

The aim of reference current signal generator is to separate the harmonic and reactive components from the load current. The main characteristic of this method is the direct derivation of the compensating component from the load current, without the use of any reference frame transformation [17].

The block diagram of the direct testing and calculating method is shown in Fig. 3. In the circuit, the distorted load current $\left(\mathrm{I}_{\mathrm{L}}\right)$ is filtered to extract the fundamental component by low pass filter (LPF) then multiplies by peak value to produce $\left(\mathrm{I}_{\mathrm{M}}\right)$. PLL generates a signal $(\omega)$ synchronized with the source voltage $\left(\mathrm{V}_{\mathrm{S}}\right)$. The calculated current signal $\left(\mathrm{I}_{\mathrm{M}}\right)$ is synchronized with the respective source voltage $\left(\mathrm{V}_{\mathrm{S}}\right)$ through the application of PLL. The output signal from PLL $(\omega)$ is then multiplied by the amplitude of the fundamental component to obtain the 
required source current $\left(I_{S}^{*}\right)$. The calculated current $\left(I_{S}^{*}\right)$ is subtracted from the load current $\left(\mathrm{I}_{\mathrm{L}}\right)$ to have the required filter current $I_{f}^{*}$ (Reference Current signal).

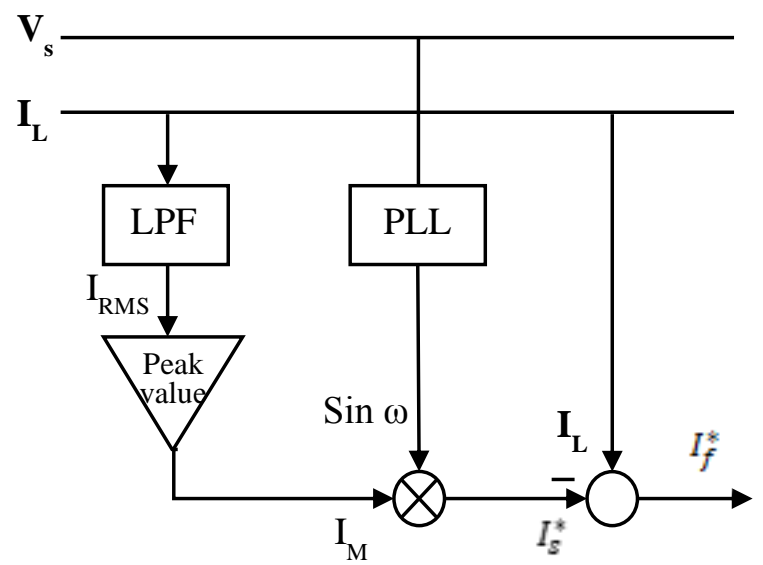

Fig. 3 Block diagram of the direct testing and calculating method

\subsection{Hysteresis current control conclusion}

The third stage of the shunt APF control circuit is generating appropriate gating signals for the power switches that forces the filter current $\left(\mathrm{I}_{f}\right)$ signal to follow its estimated reference current signal $\left(I_{f}^{*}\right)$ within a certain tolerance band to reduce the current error. This control scheme is shown in Fig. 4. In this control scheme, a signal deviation $(H)$ is designed and imposed on $I_{f}^{*}$ to form the upper and lower limits of a hysteresis band. Hysteresis current controller with a fixed $H$. To obtain a compensation current $\left(I_{f}\right)$ with switching ripples as small as possible, the value of $H$ can be reduced. However, doing so results in higher switching frequency. Thus, increases losses on the switching transistors. The advantages of using the Current hysteresis control are its excellent dynamic performance and controllability of the peak-to-peak current ripple within a specified hysteresis [18].

Fig. 5 Shows the Gating signal generation by hysteresis current control technique. An error signal (e) is used to control the switches in an inverter. This error is the difference between the desired filter current $\left(I_{f}\right)$ and its estimated reference current signal $\left(I_{f}^{*}\right)$ as $\left(\mathrm{e}=\Delta \mathrm{I}=\mathrm{I}_{f}-I_{f}^{*}\right)$.

When the error reaches an upper limit as $\Delta \mathrm{I} \geq \mathrm{H} / 2$, the transistors are switched to force the current down. When the error reaches a lower limit as $\Delta \mathrm{I} \leq-\mathrm{H} / 2$, the current is forced to increase.

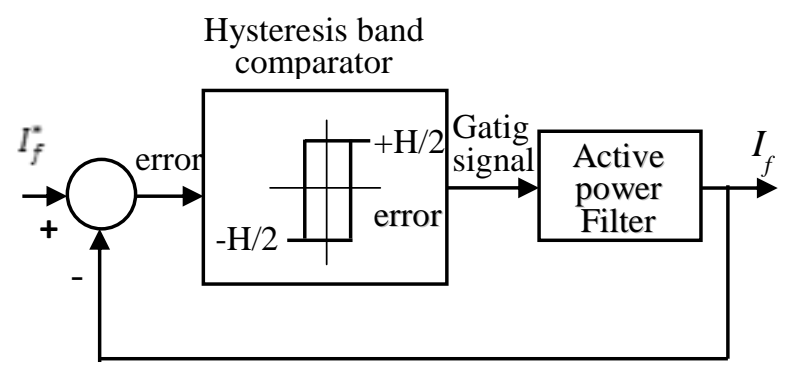

Fig. 4 Block diagram of current hysteresis control technique 


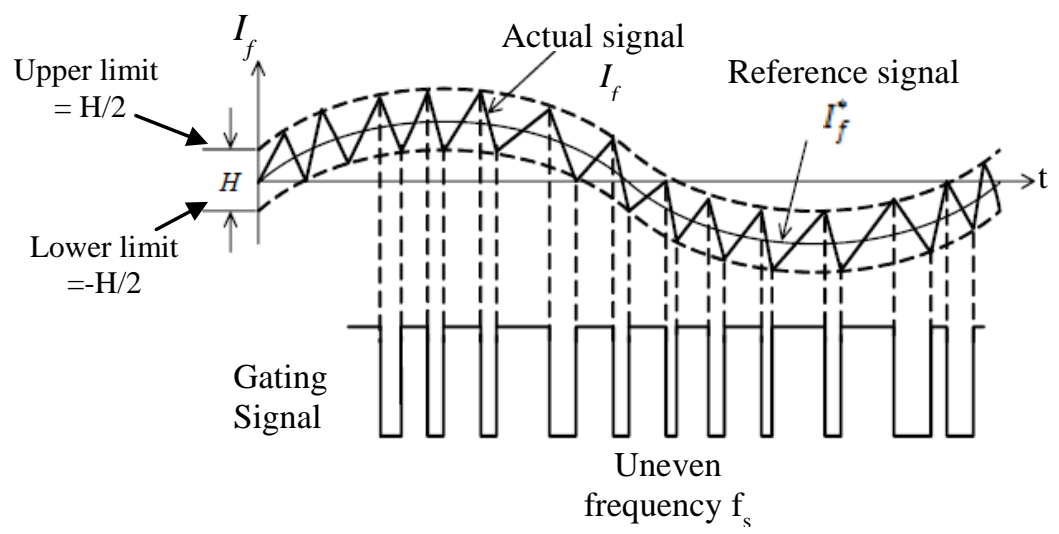

Fig. 5 Gating signal generation by hysteresis current control technique

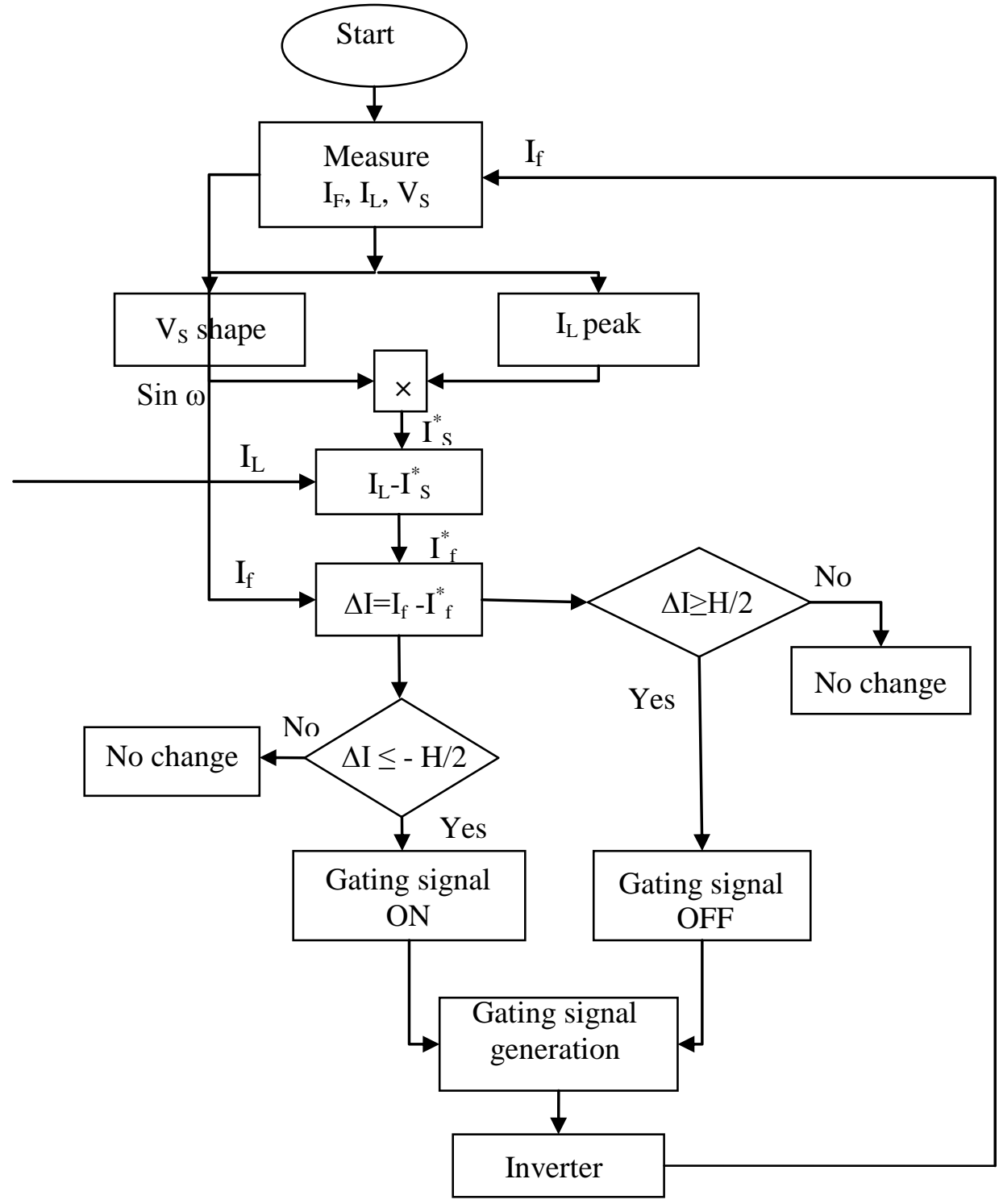

Fig. 6 Flow chart for the proposed control process 


\section{Simulation Results}

The Matlab/Simulink simulation tool [19] used to develop a model that allow the simulation and testing of the DTC theory calculations Fig. 6 Shows Flow chart for the controller of the shunt active power filter. The flow chart procedures are described in steps:

a) Measured the variable parameters $\left(\mathrm{I}_{\mathrm{F}}, \mathrm{I}_{\mathrm{L}}, \mathrm{V}_{\mathrm{S}}\right)$.

b) Extract the fundamental component of load current peak value $\left(I_{L}\right.$ peak) from the measured $\mathrm{I}_{\mathrm{L}}$.

c) Extract the shape of source voltage $\left(\mathrm{V}_{\mathrm{S}}\right.$ shape $)$ from the measured $\mathrm{V}_{\mathrm{S}}$.

d) Generate the reference source current signal $\left(I_{S}^{*}\right)$ by multiply the second and third steps.

e) Generate the reference filter current signal $\left(I_{f}^{*}\right)$ by subtract the reference source current signal $\left(I_{S}^{*}\right)$ from the load current signal $\left(\mathrm{I}_{\mathrm{L}}\right)$.

f) Subtract the reference filter current signal $\left(I_{f}^{*}\right)$ from the filter current signal $\left(\mathrm{I}_{\mathrm{F}}\right)$ to obtain error signal $(\Delta \mathrm{I})$.

g) If the error signal $(\Delta)$ equal or greater than the half value of signal deviation $(H)$ then the gating signal off will be obtained.

h) If the error signal $(\Delta \mathrm{I})$ don't equal or greater than the half value of signal deviation $(H)$ then no change.

i) If the error signal $(\Delta \mathrm{I})$ equal or smaller than the negative half value of signal deviation $(H)$ then the gating signal on will be obtained.

j) If the error signal $(\Delta \mathrm{I})$ don't equal or smaller than the negative half value of signal deviation $(H)$ then no change.

k) The pulses generated through steps 7 and 9 will be obtained to delivered to the inverter switches and the steps will be repeated as well as the system under operation.

Shunt Active Filtering (SAF) operation has been simulated using the MATLAB/SIMULINK. The system parameters considered for the study of APF for DTCM controller with hysteresis current controller are given in Table 1

Table 1 APF System Parameters

\begin{tabular}{l|l}
\hline \hline \multicolumn{1}{c|}{ System Parameters } & Value \\
\hline Line Voltage & $380 \mathrm{~V}$ \\
\hline Supply Frequency & $50 \mathrm{HZ}$ \\
\hline $\begin{array}{l}\text { Source Impedance:(Resistance Rs, } \\
\text { Inductance Ls) }\end{array}$ & $(1 \Omega, 1 \mathrm{mH})$ \\
\hline Diode rectifier load resistance ( R1, R2) & $30 \Omega, 15 \Omega$ \\
\hline $\begin{array}{l}\text { Filter Impedance:(Resistance } \mathrm{R}_{\mathrm{f}}, \text { inductance } \\
\left.\mathrm{L}_{\mathrm{f}}\right)\end{array}$ & $(1 \Omega, 1 \mathrm{mH})$ \\
\hline Dc side capacitance & $250 \mu \mathrm{F}$ \\
\hline \hline
\end{tabular}

Fig. 7 shows the simulation results $V_{s}, I_{s}$ and $I_{L}$ of the system before compensation. Fig. 8 presents the simulation results after compensation. As seen $I_{S}$ is sinusoidal and in phase with $V_{s}$. Fig. 9 shows simulation results for $I_{s}$ harmonic spectrum before and after compensation. Before harmonic compensation the THD of the supply current was $15.71 \%$ and after the harmonic compensation, it was reduced to $3.37 \%$ which complies with the IEEE 519 harmonic standards [20]. The power factor is increase from 0.51 before compensation to 0.989 after compensation. 


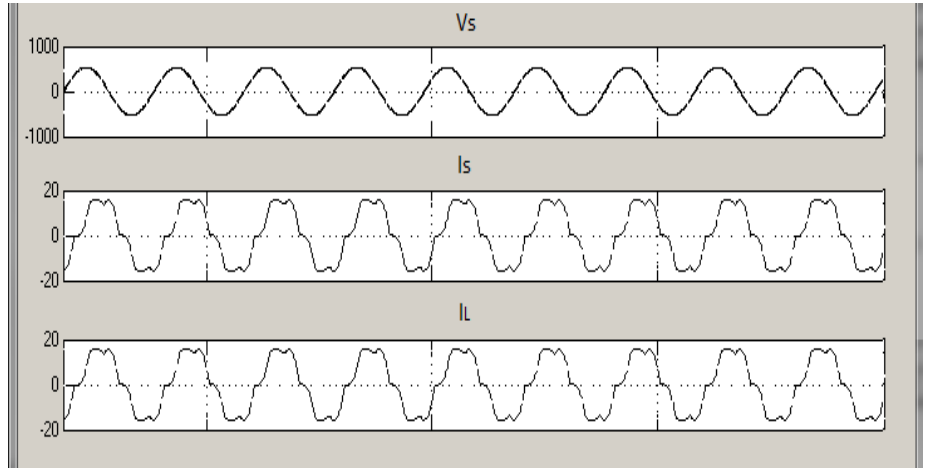

Fig. 7 simulation results for source voltage $\left(V_{s}\right)$, source current $\left(I_{s}\right)$ and load current $\left(I_{L}\right)$ before compensatin

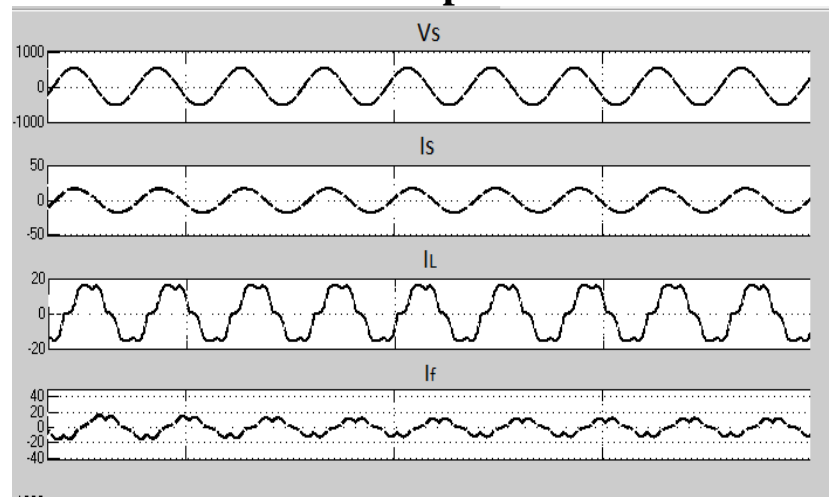

Fig. 8 waveforms of source voltage, source current, load current and filter current after compensating
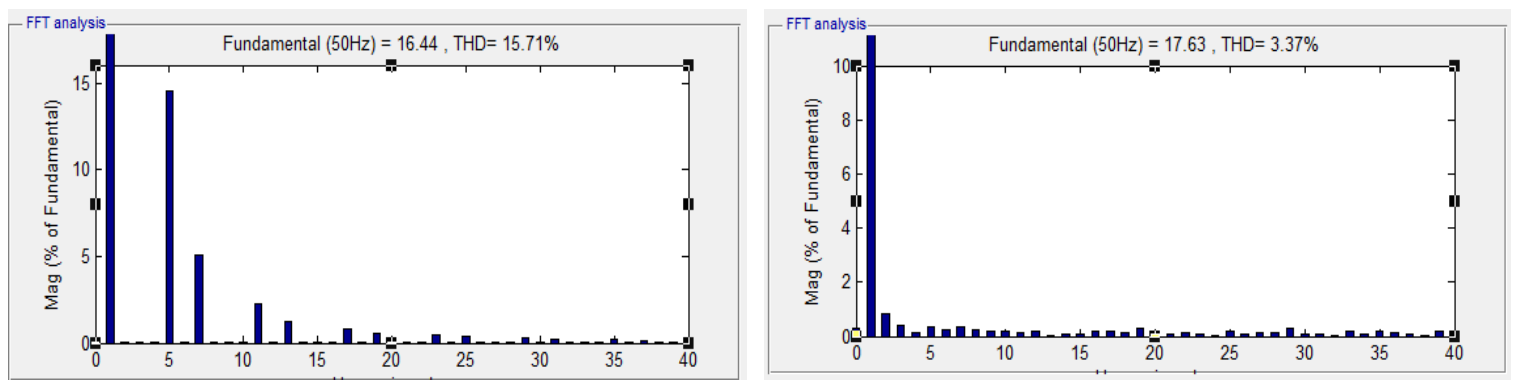

Fig. 9 (a) Input current harmonic spectrum before compensating (b) Input current harmonic spectrum after compensating

\section{Conclusion}

In this paper a direct testing and calculating (DTC) approach theory based three-phase shunt active power filter has been proposed. The simulating results demonstrate the validity of the proposed SAPF for compensating reactive power and current harmonic components to improve the power factor. The THD of the source current is reduced below the 5\% limit imposed by IEEE STD. 519-1992 standard and the power factor close to unity for nonlinear load using the SAPF. 


\section{References}

[1] Adam, G., Stan, A. and Livinţ, G., "A Matlab-Simulink Approach To Shunt Active Power Filters", Proceedings of 25th European Conference on Modelling and Simulation 2011, pp. 205-210.

[2] Alex, S. L. and Braz, F., "Analysis of Passive Filters for High Power Three-level Rectifiers", Industrial Electronics, IECON, 34th Annual Conference of IEEE, Nov 10-13 2008, pp. 3207-3212.

[3] Rachid, D. and Slimane, S., "Power quality and cost improvement by passive power filters synthesis using ant colony algorithm", Journal of Theoretical and Applied Information Technology, published by JATIT \& LLS 2005 - 2011, pp. 70-79.

[4] Pottker, F. and Barbi, I., "Power Factor Correction of Non-Linear Loads Employing a Single Phase Active Power Filter: Control Strategy, Design Methodology and Experimentation", PESC, (IEEE), Jun 22-27, 1997, pp. 412-417.

[5] Imani, J. H. R., Mohamed, A., Shareef, H. and Subiyanto., "A New Method for Calculating the Reference Current of Shunt Active Power Filters Based on Recursive Discrete Fourier Transform", International Review on Modelling and Simulations, Aug 2012, pp. 1439-1446.

[6] Kirti, K., Anil, K. C. and Veeresh, C., "Modeling of Frequency Domain Control of Shunt Active Power Filter Using MATLAB/Simulink and Power System Blockset", International Journal of Engineering Research and Applications, Vol. 3, Issue 4, Jul-Aug 2013, pp. 21092114.

[7] Siyu, L., Wenxin, L. and David, C., "Active power filter for three-phase current harmonic cancellation and reactive power compensation", American Control Conference, MO, USA, Jun 10-12, 2009, pp. 2140-2147.

[8] Metin, K. and Ozdemir, E., "Operation of shunt active power filter under unbalanced and distorted load conditions", Electrical and Electronics Engineering, ELECO, International Conference on. IEEE, 2009, pp. 1-92-1-96.

[9] Moinuddin, K. S. and Sanker, B. R., "Instantaneous Power theory based Active Power Filter: A Matlab/Simulink approach", Journal of Theoretical and Applied Information Technology, 2008, pp. 536-541.

[10] Rathika, P. and Devaraj, D., "Fuzzy Logic-Based Approach for Adaptive Hysteresis Band and DC Voltage Control in Shunt Active Filter ", International Journal of Computer and Electrical Engineering, Vol. 2, No. 3, Jun, 2010, pp. 1793-8163.

[11] Emílio, F. C., Júlio, S. M. and João, L. A., "Simulation Results of a Shunt Active Power Filter with Control Based on p-q Theory", International Conference on Renewable Energies and Power Quality Vigo, Espanha, Abril 9-12, 2003, pp. 1-6.

[12] Charles, S. and Bhuvaneswari, G., "Comparison of Three Phase Shunt Active Power Filter Algorithms", International Journal of Computer and Electrical Engineering, IEEE, Vol. 2, No. 1, February, 2010, pp. 175-180.

[13] Murat, K. and Ozdemir, E., "An adaptive hysteresis band current controller for shunt active power filter", Journal of Electric power systems research, elsevier, science direct, 2005, pp. 113-119.

[14] SmitaSinghai., Bharti, D. and Dimat, R., "Implementation of Active Harmonic Filter with MATLAB/Simulink to compensate Non-Linear Loads", International Journal of Digital Application and Contemporary research Vol. 1, Issue 9, April 2013.

[15] Doğan, H. and Akkaya R., "A Simple Control Scheme for Single-Phase Shunt Active Power Filter with Fuzzy Logic Based DC Bus Voltage Controller", Proceedings of the International Multi Conference of Engineers and Computer Scientists, Vol. II IMECS, Hong Kong, March 18 - 20, 2009. 
[16] El-Kholy, E. E., El-Sabbe, A., El-Hefnawy, A. and Mharous, H. M., “Three-phase active power filter based on current controlled voltage source inverter", International Journal of Electrical Power \& Energy Systems, 2006, pp. 537-547.

[17] Donghua, C. and Shaojun, X., "Review of the control strategies applied to active power filters", IEEE International Conference on Electric Utility Deregulation Restructuring and Power Technologies, Hong Kong, April 2004, pp. 666-670.

[18] Zainal, S., Tan, P. C. and Awang, J., "Harmonics Mitigation Using Active Power Filter: A Technological Review", journal of Faculty of Electrical Engineering Universiti Teknologi Malaysia, Vol. 8, No. 2, 2006, pp.17-26.

[19] Simulink - Model-Based and System-Based Design, Modelling, Simulation, Implementation, version 6.5, The MathWorks.

[20] IEEE 519-1992 Standard. Power System Harmonics. Bulletin No. 8803PD9402, Raleigh, NC, U.S.A, August 1994. 